\title{
Exercise Log
}

National Cancer Institute

\section{Source}

National Cancer Institute. Exercise Log. NCI Thesaurus. Code C156898.

A paper or electronic record of an individual's fitness, exercise, or other physical activities.

This usually includes a description of the type of activity and a entry for time at the activity. Other information might include specific details of the activity and subjective feelings about the activity and the individual's perceived effort and fitness. 